\title{
Verification of learner's differences by team-based learning in biochemistry classes
}

\author{
Kwang Ho Mun ${ }^{1}$ and Kyo Cheol Mun ${ }^{2}$ \\ Departments of ${ }^{1}$ Preventive Medicine and Public Health and ${ }^{2}$ Biochemistry, Keimyung University School of Medicine, \\ Daegu, Korea
}

Purpose: We tested the effect of team-based learning (TBL) on medical education through the second-year premedical students' TBL scores in biochemistry classes over 5 years.

Methods: We analyzed the results based on test scores before and after the students' debate. The groups of students for statistical analysis were divided as follows: group 1 comprised the top-ranked students, group 3 comprised the low-ranked students, and group 2 comprised the medium-ranked students. Therefore, group T comprised 382 students (the total number of students in group 1, 2, and 3). To calibrate the difficulty of the test, original scores were converted into standardized scores. We determined the differences of the tests using Student t-test, and the relationship between scores before, and after the TBL using linear regression tests.

Results: Although there was a decrease in the lowest score, group $T$ and 3 showed a significant increase in both original and standardized scores; there was also an increase in the standardized score of group 3. There was a positive correlation between the pre- and the post-debate scores in group $T$, and 2. And the beta values of the pre-debate scores and "the changes between the pre- and post-debate scores" were statistically significant in both original and standardized scores.

Conclusion: TBL is one of the educational methods for helping students improve their grades, particularly those of low-ranked students.

Key Words: Medical schools, Premedical education, Small group teaching method, Team-based learning

\section{Introduction}

Team-based learning (TBL) is a method that allows students to self-study by questioning, discussing, and teaching with each other, focusing on a given topic of their studies each time [1,2]. The term and concept of TBL was first introduced by Larry Michaelsen, at Oklahoma University College of Business, and it was first introduced to medical education by Boyd Richards at Wake Forest University $[3,4]$. The spread and development of TBL was accompanied by the publication of the book, "Team-based learning: a transformative use of small groups in college teaching" by Michaelsen et al. [3] in 2002, and the opening of the homepage (http://www.teambasedlearning.org) in 2004 [4].

In medical school, problem-based learning (PBL) and TBL are recommended as substitute for classic teaching
Received: September 14, 2017 - Revised: October 20, 2017 - Accepted: November 8, 2017 Corresponding Author: Kyo Cheol Mun (https://orcid.org/0000-0002-7882-6174) Department of Biochemistry, Keimyung University School of Medicine, 1095 Dalgubeol-daero, Dalseo-gu, Daegu 42601, Korea

Tel: +82.53.580.3851 Fax: +82.53.580.3717 email: mun@kmu.ac.kr
Korean J Med Educ 2017 Dec; 29(4): 263-269.

https://doi.org/10.3946/kjme.2017.72

eISSN: 2005-7288

(C) The Korean Society of Medical Education. All rights reserved. This is an open-access article distributed under the terms of the Creative Commons Attribution Non-Commercial License (http:// creativecommons.org/licenses/by-nc/3.0/), which permits unrestricted non-commercial use, distribution, and reproduction in any medium, provided the original work is properly cited. 
methods and have been applied since [1-8]. Both methods emphasize encouraging of students' involvement as well as self-studying [1-8]. However, the major disadvantage of PBL is that students can be misguided when the debate does not follow the intended plan [8]. On the contrary, TBL is able to correct this misguidance. By providing study materials prior to class, students are able to study and debate according to the plan. Moreover, with clarification review by professors, students are able to gain precise medical knowledge as need [1-4]. Recently, many educational theories have been incorporated into medical education [1], and TBL is known as one of the better teaching methods for improving learning effectiveness $[9,10]$. Therefore, in this study, the effectiveness of TBL in medical education was analyzed through the TBL scores of student groups in second-year premedical biochemistry classes over 5 years.

\section{Methods}

\section{Subjects}

From the second semester of the 2011 school year to the second semester of the 2015 school year (the Korean school year starts in March and ends in December), premedical students at Keimyung University School of Medicine were selected for this study. A total of 382 students, or approximately 80 in each school year, were selected. This study was approved by the Institutional Review Board of Keimyung University, Korea (number: 40525-201706-HR-42-01).

\section{Team-based learning recurring steps}

The block format of TBL was applied to students once throughout the year, during the second semester of second year of the premedical school. Before the TBL classes, students were given a brief explanation of the process and evaluation method for 10 minutes. The TBL process was performed according to the existing methods [2,5,10-13]. The process was conducted as follows with individual readiness assurance test, team readiness assurance test, instructor clarification review, and individual achievement test after the debate.

\section{1) Advance assignment}

The chapter on nucleic acid, from the "Principles of medical biochemistry" of Meisenberg and Simmon had been presented to the students in advance with learning objectives. This subject was selected as the basis of the subject was studied during the first year of premedical school during molecular biology class. They studied the chapter by themselves during the first year or the first semester of the second year.

\section{2) Individual readiness assurance test}

Each individual student completed a set of multiplechoice 20 questions that focuses on the learning goals for 40 minutes.

\section{3) Team assurance test}

After the individual readiness assurance test, students were asked to move to self-study room where five to six students were gathered in a group for the debate. In each room, students were asked to solve same set of questions that each had answered individually in the readiness assurance test. At this stage, however, each team was asked to answer through a consensus-building debate for 2.5 hours. Students were asked to talk freely about each question, based on their knowledge from their textbook, but were not allowed to search on the Internet in order to prevent access to nonprofessional knowledge.

\section{4) Instructor clarification review}

After discussing as a team, the teams were asked to submit the correct answers. After the debate, students were gathered together and under the inspection of the 
instructor in the classroom, they had a debate on each team's answers for 2.5 hours. Instructor chose one person from a random group to talk about the group's answer and give the reason for their choice. Then, other teams were led to argue about the answer.

\section{5) Individual achievement test after debate}

After the debate, each student completed a new set of 20 multiple-choice questions that focused on their learning goals for 40 minutes.

\section{Data analysis}

The test results were analyzed based on the test scores prior to the debate (individual readiness assurance test) and the test scores after the debate (individual achievement test after debate).

\section{1) Grouping for statistical analysis}

The groups of students for statistical analysis were divided as follows based on their pre-debate test scores (individual readiness assurance test). In group 1, there were ties in some of the scores; thus, it comprised 103 students, which was $27.0 \%$ of the total number of students, although it was meant to comprise the top $20 \%$ of the students. Next, group 3 comprised the lowest $20 \%$ in the pre-debate test. Finally, in group 2 there were also ties in some of the scores; thus, it comprised 96 students, or $25.1 \%$. Thus, group 2 comprised the medium-ranked students not in group 1 or group 3 . Group $\mathrm{T}$ therefore comprised 382 student participants (this is the total of participants in groups 1, 2, and 3).

\section{2) Statistics}

To correct the difficulty of the tests, we converted the participants' original scores into standardized scores with a mean of 100.0 and a standard deviation (SD) of 20.0 points. We analyzed only the scores from the pre- and post-debate tests. Then we analyzed the original and standardized mean scores, the differences between the pre- and post-debate scores, and lastly their correlations.

We present all descriptive data as mean $\pm \mathrm{SD}$, and we analyzed the differences between the groups with the Student t-test. Then we used linear regression tests to evaluate the relationship between scores before and after TBL, analyzing both standardized and original scores. Our accepted level for evaluating statistical significance was $p<0.05$. All of these analyses were performed with the IBM SPSS ver. 23.0 (IBM Corp., Armonk, USA).

\section{Results}

\section{Changes in original score after debate}

Table 1 shows the changes in participants' original scores after the debate. The mean of group T with 382 students was $55.0 \pm 19.2$ points pre-debate, but increased by 2.6 points to $57.6 \pm 19.6$ points post-debate $(\mathrm{p}<0.001)$. The mean of group 1, the top-ranked students, was $82.6 \pm 6.8$ points pre-debate, but decreased by 4.5 points

Table 1. Verification of Original Scores before and after Debate between the Different Learner Groups

\begin{tabular}{rllr}
\hline \multicolumn{1}{c}{ Group } & Before debate & After debate & Changes \\
\hline Group T) $^{\text {al }}$ & $55.0 \pm 19.2$ & $57.6 \pm 19.6^{* * *}$ & 2.6 \\
Group $^{\text {b) }}$ & $82.6 \pm 6.8$ & $78.1 \pm 12.2^{* *}$ & -4.5 \\
Group 2 & $55.4 \pm 9.8$ & $56.6 \pm 17.2$ & 1.2 \\
Group 3 $^{\text {d) }}$ & $28.3 \pm 7.7$ & $41.3 \pm 14.5^{* * *}$ & 13.1 \\
\hline
\end{tabular}

Data are presented as mean \pm standard deviation.

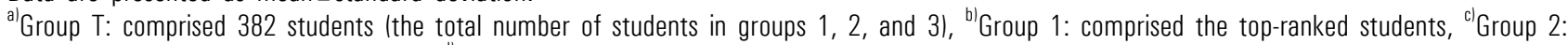
comprised the medium-ranked students, ${ }^{d \mid}$ Group 3 : comprised the low-ranked students. ${ }^{* *} p<0.01,{ }^{* * *} p<0.001$. 
to $78.1 \pm 12.2$ points post-debate $(\mathrm{p}<0.01)$. The mean of group 2, the medium-ranked students, was $55.4 \pm 9.8$ points pre-debate, but $56.6 \pm 17.2$ post-debate without statistical significance. The mean of group 3, the lowranked students, was $28.3 \pm 7.7$ points pre-debate, but increased by 13.2 points to $41.3 \pm 13.1$ points post-debate ( $\mathrm{p}<0.001$ ). Hence, according to the results of the original scores the overall score (group $\mathrm{T}$ ) and the scores of low-ranked students (group 3) showed a significant increase.

\section{Changes in standardized score after debate}

Table 2 shows the changes in post-debate standardized scores. The pre-debate mean of group $\mathrm{T}$ was $100.0 \pm 20.0$ points. The pre-debate mean of group 1 was 12.8.8 \pm 7.1 , but decreased by 7.7 points post-debate to $121.0 \pm 12.4$ $(\mathrm{p}<0.01)$. The pre-debate mean of group 2 was 100.4 \pm 10.2 points, but $99.1 \pm 17.7$ points post-debate without statistical significance. The pre-debate mean of group 3 was $72.2 \pm 8.1$ points, but increased post-debate by 11.3 points to $83.5(\mathrm{p}<0.001)$.

Hence, according to the standardized score results, there was an increase in the standardized scores of the low-ranked students (group 3). However, there was a decrease in the standardized scores of the top-ranked students (group 1).

\section{Linear regression analysis for the original and standardized scores}

Table 3 shows the changes in post-debate standardized scores. Beta values for original scores were 0.664 in group $\mathrm{T}$ ( $\mathrm{p}<0.001), 0.320$ in group $1(\mathrm{p}<0.01), 0.442$ in group 2 ( $<<0.001$ ), and 0.170 in group 3 (not significant). Beta values for standardized scores were 0.664 in group $\mathrm{T}(\mathrm{p}<0.001), 0.320$ in group $1(\mathrm{p}<0.01), 0.442$ in group 2 ( $<<0.001$ ), and again 0.170 in group 3 (not significant). In summary, we find a positive relationship between the pre-debate and the post-debate scores.

Table 2. Verification of Standardized Score before and after Debate between the Different Learner Groups

\begin{tabular}{rlcc}
\hline Group & Before debate & After debate & Changes \\
\hline Group $^{\text {al }}$ & $100.0 \pm 20.0$ & $100.0 \pm 20.0$ & 0 \\
${\text { Group } 1^{\text {bl }}}_{\text {Group 2 }}^{\text {cl }}$ & $128.8 \pm 7.1$ & $121.0 \pm 12.4^{* * *}$ & -7.7 \\
Group 3 $^{\text {d) }}$ & $100.4 \pm 10.2$ & $99.1 \pm 17.6$ & -1.4 \\
\hline
\end{tabular}

Data are presented as mean \pm standard deviation.

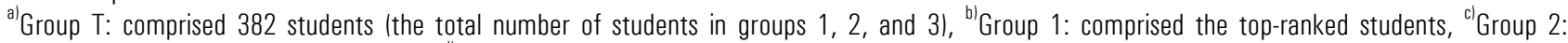
comprised the medium-ranked students, ${ }^{d \mathrm{C}}$ Group 3: comprised the low-ranked students. ${ }^{* *} p<0.001$.

Table 3. Linear Regression Analysis for the Original and Standardized Scores

\begin{tabular}{|c|c|c|c|c|}
\hline \multirow{2}{*}{ Group } & \multicolumn{2}{|c|}{ Original score } & \multicolumn{2}{|c|}{ Standardized score } \\
\hline & $\beta$ & $95 \% \mathrm{Cl}$ & $\beta$ & $95 \% \mathrm{Cl}$ \\
\hline Group $\mathrm{T}^{\mathrm{al}}$ & $0.664^{* * *}$ & 0.600 to 0.754 & $0.664^{* * *}$ & 0.589 to 0.739 \\
\hline Group $1^{\text {bl }}$ & $0.320^{* *}$ & 0.169 to 0.978 & $0.320^{* *}$ & 0.054 to 0.311 \\
\hline Group $2^{c 1}$ & $0.442^{* * *}$ & 0.574 to 0.984 & $0.442^{* * *}$ & 0.189 to 0.324 \\
\hline Group $3^{\text {dl }}$ & 0.170 & -0.104 to 0.739 & 0.170 & -0.030 to 0.215 \\
\hline
\end{tabular}

Cl: Confidence interval.

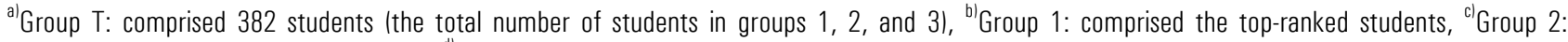
comprised the medium-ranked students, ${ }^{\text {d) }}$ Group 3 : comprised the low-ranked students. ${ }^{* *} p<0.01,{ }^{* * *} p<0.001$. 
Table 4. Linear Regression Analysis of the Changes in Original and Standardized Scores

\begin{tabular}{|c|c|c|c|c|}
\hline \multirow{2}{*}{ Group } & \multicolumn{2}{|c|}{ Changes of original score } & \multicolumn{2}{|c|}{ Changes of standardized score } \\
\hline & $\beta$ & $95 \% \mathrm{Cl}$ & $\beta$ & $95 \% \mathrm{Cl}$ \\
\hline Group $T^{\text {al }}$ & $-0.471 * * *$ & -0.583 to -0.358 & $-0.500 * * *$ & -0.612 to -0.388 \\
\hline Group $1^{\text {bl }}$ & -0.426 & -0.831 to -0.022 & $-0.148^{*}$ & -0.282 to -0.014 \\
\hline Group $2^{\text {cl }}$ & $-0.221^{*}$ & -0.426 to -0.016 & $-0.096^{*}$ & -0.178 to -0.014 \\
\hline Group $3^{\mathrm{dl}}$ & $-0.683^{* *}$ & -1.104 to -0.261 & $-0.184^{* *}$ & -0.294 to -0.074 \\
\hline
\end{tabular}

Cl: Confidence interval.

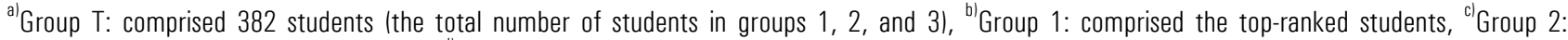
comprised the medium-ranked students, ${ }^{\text {d) }}$ Group 3 : comprised the low-ranked students. ${ }^{*} p<0.05,{ }^{* *} p<0.01,{ }^{* * *} p<0.001$.

\section{Linear regression analysis for the changes in original and standardized scores}

Table 4 shows the changes in standardized scores after debate. Beta values for the changes in original scores were -0.471 in group $\mathrm{T}(\mathrm{p}<0.001),-0.426$ in group 1 $(\mathrm{p}<0.05),-0.221$ in group $2(\mathrm{p}<0.05)$, and -0.683 in group $3(p<0.01)$. Beta values for the changes in standardized scores were -0.500 in group $\mathrm{T}(\mathrm{p}<0.001),-0.148$ in group $1(\mathrm{p}<0.05),-0.096$ in group $2(\mathrm{p}<0.05)$, and -0.184 in group $3(\mathrm{p}<0.001)$. In summary, we find the beta values of the pre-debate scores and "the changes between the pre- and post-debate scores" were statistically significant in both the original and standardized scores.

\section{Discussion}

Among small group studies, PBL and TBL are recommended as substitute for classic teaching methods in medical school. Both PBL and TBL emphasize the encouragement of students' involvement as well as self-studying [1-8]. The advantage of PBL is that it leads to self-studying, increasing students' thinking ability, and so forth. However, the major disadvantage of PBL is that students can be misguided when the debate goes in a wrong direction [8]. On the contrary, TBL has a way to revise this misguidance. By providing studying materials prior to the class, students are able to study and debate in a right direction. Moreover, by clarification review by professors, students are able to gain precise medical knowledge at need [1-4]. Recently, many educational theories have been incorporated into medical education [1], and TBL is known as one of the better teaching methods for improving learning effectiveness $[9,10]$. However, there has not been a study showing for which group of students TBL is effective. Therefore, in this study, the effectiveness of TBL in medical education was analyzed through the TBL scores of student groups in second-year premedical biochemistry classes over 5 years.

Although, we followed the TBL process according to the existing methods $[2,5,10-13]$, and its concrete points are as follows. To summarize the results of post-TBL debate, it was sometimes necessary to monitor students' discussion scenarios to prevent students' active participation, which we judged it necessary to restrain. There was also a need for students to abstain from using the Internet to prevent access to nonprofessional knowledge. It was judged that five to 10 questions per hour were appropriate for the debate, and about 15 questions were suitable for 2 hours. And during the instructor clarification review, the lowest-grade students in each group were asked to present their team answers with their teams' reasoning. We believed their excellent presentation opportunity would improve their learning 
effectiveness by publicly pointing out their additional scores and deductions when their presentations were not good. Problems unknown to all of the students were solved by letting students know only the key points, followed by self-study. If a student was asked a question that they did not understand, other students had to answer rather than the professor. If there were a point no debating was done, the professor asked the question to stimulate discussion. If one to three students actively debated, additional points were given. A single professor was capable of questioning, reviewing and proceeding the TBL process $[3,4,9]$. Considering the amount of study that medical students must do, it was reasonable to test them with a review items rather than preparation items. According to the results of this study's TBL scores, despite the decrease in the lowest score, the overall score (group T) and the score of low-ranked students (group 3) showed a significant increase in their both original and standardized scores. However, there was a decrease in the standardized scores of the top-ranked students (group 1). There was also a positive correlation between the pre-debate and the post-debate scores of groups $\mathrm{T}$ and 2. Additionally, the beta values of the pre-debate scores and "the changes between the pre- and postdebate scores" were statistically significant in the both the original and standardized scores of all groups. This confirms results from other researchers that TBL is helpful for improving grades [8,14-16], particularly those of low-ranked students.

There are some limitations of this study. First, we tested students' grade only, therefore their performance and involvement were not measured in the current study. Secondly, only TBL was performed as limit of time and resources, the future study will be conducted to compare between other teaching methods, such as PBL.

We therefore conclude that with thorough preparation, TBL is one of the better educational methods for helping students improve their grades, particularly those of low-ranked students.

\section{ORCID:}

Kwang Ho Mun: https://orcid.org/0000-0001-7489-4738;

Kyo Cheol Mun: https://orcid.org/0000-0002-7882-6174

Acknowledgements: None.

Funding: None.

Conflicts of interest: None.

Author contributions: All authors had full access to the data of this study, and have full responsibility for the integrity and accuracy of the data. Concept and design of the work: all authors; data collection: KCM; statistical analysis of the data and interpretation: KHM; drafting of the manuscript: all authors; revision of the manuscript: all authors; final approval of the version: all authors.

\section{References}

1. Kim S. How to apply small group teaching method. Korean J Med Educ. 2014;26(2):83-86.

2. Ismail NA Effectiveness of team-based learning in teaching medical genetics to medical undergraduates. Malays J Med Sci. 2016;23(2):73-77.

3. Michaelsen LK, Knight AB, Fink LD. Team-based learning: a transformative use of small groups in college teaching. Herndon, USA: Stylus Publishing; 2004.

4. Kim S, Park JH, Yoo NJ, Lee SJ. Team-based learning for health professions education: a guide to using small groups for improving learning. Seoul, Korea: Academy Express; 2009.

5. Park KH, Park CH, Chung WJ, Yoo CJ. Implementation of a problem-based learning program combined with team-based learning. Korean J Med Educ. 2010;22(3): 225-230. 
6. Kim HY, Lee R, Lee J, Cho HJ, Park KY. Student's evaluation of problem-based learning curriculum in medical school. Korean J Med Educ. 2008;20(3): 259-264.

7. Walton HJ, Matthews MB. Essentials of problem-based learning. Med Educ. 1989;23(6):542-558.

8. David T, Patel L, Burdett K, Rangachari P. Problembased learning in medicine: a practical guide for students and teachers. London, UK: Royal Society of Medicine; 2005.

9. Park KD, Kim B, Kim T, Phyo S, Myung SJ. Is remediation program using team-based learning effective for at-risk medical students? Korean J Med Educ. 2014; 26(1):25-29.

10. Hur Y, Cho AR, Kim S. Review on the administration and effectiveness of team-based learning in medical education. Korean J Med Educ. 2013;25(4):271-277.

11. Cho AR. Tips for effective team-based learning administration in medical education. Korean J Med Educ. 2008;20(4):373-374.
12. Haidet P, Levine RE, Parmelee DX, et al. Perspective: guidelines for reporting team-based learning activities in the medical and health sciences education literature. Acad Med. 2012;87(3):292-299.

13. Parmelee D, Michaelsen LK, Cook S, Hudes PD. Team-based learning: a practical guide: AMEE guide no. 65. Med Teach. 2012;34(5):e275-e287.

14. Han HS, Lee R, Sohn IS, Lee JM, Lee KY. A study on students' academic achievement and perception of team-based learning during a medical dermatopatholgy lecture. Korean J Med Educ. 2007;19(3):257-263.

15. Cho AR, Han SI, Yoon SH, Park JH, Yoo NJ, Kim S. Methods of effective team-based learning administration and expected effects on medical education. Korean J Med Educ. 2010;22(1):47-55.

16. Chen X, Chen B, Li X, Song Q, Chen Y. Mutual benefit for foreign medical students and Chinese postgraduates: a mixed team-based learning method overcomes communication problems in hematology clerkship. Biochem Mol Biol Educ. 2017;45(2):93-96. 